\title{
A logistics sector's perspective of factors and risks within the business environment that influence supply chains' effectiveness: An explorative mixed method study
}

\author{
Authors: \\ Johanna A. Badenhorst- \\ Weiss ${ }^{1}$ \\ Beverley J. Waugh ${ }^{1}$

Affiliations:
'Department of Business
Management (Purchasing
and Supply Chain
Management), University of
South Africa, South Africa
Correspondence to:
Hannie Badenhorst-Weiss
Email:
badenja@unisa.ac.za
Postal address:
PO Box 392, University of
South Africa 0003, South
Africa
Dates:
Received: 18 Feb. 2015
Accepted: 15 June 2015
Published: 11 Sept. 2015
How to cite this article:
Badenhorst-Weiss, J.A. \&
Waugh, B.J., 2015, 'A logistics
sector's perspective of
factors and risks within the
business environment that
influence supply chains'
effectiveness: An explorative
mixed method study', Journal
of Transport and Supply
Chain Management $9(1)$, Art.
\#177, 9 pages. http://dx.doi.
org/10.4102/jtscm.v9i1.177

Read online:

Scan this QR code with your smart phone or mobile device to read online.
Background: Supply chains in South Africa operate in a challenging business environment. This environment influences the efficiency and effectiveness of South African businesses and supply chains. These factors further influence the competitiveness of products produced in the country, the economic growth and development of South Africa.

Objectives: The purpose of this study was two-fold: Firstly, to obtain insight into the main business environment risks and other factors, from a logistics perspective; and secondly, to demonstrate the use of methodology not often used in logistics research - the sequential mixed method.

Method: The explorative study was conducted amongst logistics service providers and cargo owners in 2013 by means of a sequential mixed method study, consisting of a survey to determine the importance of risk factors in the business environment, followed by a qualitative study in the form of a focus group discussion to obtain richer data and insight into these risks and factors. The results of these two methods were integrated with industry literature.

Results: It was found that increasing transportation costs, operational management of infrastructure and human resources-related problems pose the biggest challenges in the logistics industry. In addition, it was found that the mixed method research study has application possibilities in logistics research.

Conclusion: The factors identified as particularly problematic for the logistics industry, namely ineffective operational management of infrastructure, the general conditions in the labour market and increasing costs (to some extent) are outside the control of individual organisations. However, organisations can control how they react and mitigate these risk factors. It is shown that these factors and risks can change overnight. The use of the explorative mixed method in obtaining qualitative and quantitative inputs and integrating it with existing literature proved to be a workable and usable methodology.

\section{Introduction}

There is a critical need for the improvement of South Africa's freight transportation system, based on the vulnerability of the country's logistics performance and competitiveness, particularly as it relates to transport costs. (Simpson \& Havenga 2012:51)

However, if one looks at the Logistics Performance Index (LPI) of South Africa the situation does not look too bad. A slight negative trend is however observed since South Africa's LPI has decreased to 34th out of 160 countries in 2014 from 23rd out of 155 countries in 2012 (The World Bank 2012, 2014). South Africa is still performing well if compared to some developing countries. For example, South Africa, as one of the BRICS countries, is closely behind China, but far ahead of Russia, India and Brazil on the index.

South Africa is part of and competes in the global economy. Efficient and effective logistics operators (cargo owners and logistics service providers) play an important role in the competitiveness of the economy. The effectiveness and efficiency of logistics operators and their supply chains can be

Note: This article makes a contribution to literature in that it reports on the findings of an explorative sequential mixed method research study among logistics stakeholders into major factors and risks within the business environment pertaining to supply chains in South Africa. It is also partially based on the authors' article 'Business environmental factors affecting South Africa's supply chains and economic growth and development', published in Problems and Perspectives in Management, Vol. 12, Issue 4, 2014: http://businessperspectives. org/journals_free/ppm/2014/PPM_2014_04_spec.issue_Weiss.pdf. Journal of Transport and Supply Chain Management was granted an one-time, non-exclusive right to republish this article.

Copyright: @ 2015. The Authors. Licensee: AOSIS OpenJournals. This work is licensed under the Creative Commons Attribution License. 
impacted by many internal factors such as technology used, management skills, corporate culture, inter-firm relations and collaboration. However, the effectiveness and efficiency of logistics operators and supply chains can also be influenced by various factors in the business environment, such as the provision of infrastructure, operational management of the infrastructure, the availability of human resources and a regulatory framework conducive to business and trade. Risks and constraints in the business environment may negatively impact logistics organisations and the supply chains within which they operate (Badenhorst-Weiss \& Waugh 2014:238). These risks and constraints pose enormous challenges to organisations and stakeholders must therefore consider all the aspects that may impact on the performance of supply chains (Bredell \& Walters 2007:2).

As with any risks, in order for them to be managed, they must be clearly identified and their implications and importance understood by all involved (Bredell \& Walters 2007:2). This research seeks to explore, by means of a mixed method study, key risk factors in the business environment that constrain the effectiveness and efficiency of logistics operators in South Africa.

The survey part of the research study was commissioned by the South African Shippers Council (SASC), which has now changed to Southern Africa Shippers, Transport and Logistics Council (SASTALC). The objective of the study was to obtain the perceptions of logistics service providers and cargo owners about the risks and factors in the South African business environment that have an impact on their efficiency and effectiveness. This was conducted by means of a quantitative study (survey), followed by a qualitative focus group discussion to obtain richer data whilst appropriate industry related literature was searched and integrated in the study for further insight into the risks (Badenhorst-Weiss \& Waugh 2014:283).

The technological revolution accelerated globalisation created a dynamically changing world that is becoming increasingly challenging, competitive and complex as well as customised (Barloworld Logistics 2013). Globalisation and the increasing complexities impact the number of issues and the risk of supply chain disruptions as supply chains get longer, more complex and involve more partners (Hailey \& Jonasson 2013:55).

Factors and risks in the business environment that affect supply chains may change quickly, and the management of these risks is becoming one of the most important areas in supply chain management. This is demonstrated by the fact that this study was done in 2013, and although the efficiency and sufficiency of infrastructure was identified as a constraint or risk, electricity provision problems were not anticipated by the logistics industry role players involved in this study as a risk. Just over a year later the negative effect of electricity provision problems is felt by supply chains and the country as a whole.
This article seeks to make a contribution in that it reports on the findings of a sequential mixed method research study among logistics stakeholders. The article is not based on a traditional research method where a comprehensive literature study was done, upon which a research approach was developed, followed by empirical research. The need for the research was identified by industry players, and the research instrument or questionnaire was developed by them based on their own experience. The researchers and a statistical consultant assisted with the development of the technical part of the instrument. The research questionnaire is thus been seen as a practically-oriented instrument. The survey findings provided the background to a qualitative study. The qualitative study was conducted by means of a focus group discussion, to gain insight into how the risk factors are experienced by logistics role players and what they suggest to alleviate the problems. Lastly, the results of the survey and qualitative study were integrated with industry (including non-academic) literature. The approach followed is called the explorative mixed method (Creswell 2009:18) and although it is not a well-known method in logistics research, it still follows the basic scientific research principles.

\section{Logistics, supply chains and economic growth and development Logistics and supply chain management}

Logistics is concerned with the movement of goods, both incoming goods (inbound) and the distribution of goods to the next members of the supply chain and to the end customer (outbound) (Badenhorst-Weiss \& Waugh 2014:284). 'Logistics management deals with the handling, movement and storage activities within the supply chain - beginning with suppliers and ending with the customer' (Burt, Petcavage \& Pinkerton 2010:536). As logistics plays a crucial role in ensuring that customers are served with the best possible service (in terms of reliability, speed, safety, flexibility) at the lowest possible cost, managing logistics activities for maximum efficiency and effectiveness is critical (Badenhorst-Weiss \& Waugh 2014:284). Supply chain management, on the other hand, entails the planning and management of all activities involved in sourcing and procurement, conversion and all logistics management activities. It also includes co-ordination and collaboration with channel partners, which can besuppliers, intermediaries, third-party service providers and customers (Pienaar \& Vogt 2012:8). It is clear that logistics is an important part of supply chain management and is often used as a synonym - 'supply chains consist of logistics systems of networks' (Gattorna 2010:11). Inefficiencies in one part of the supply chain will have a negative impact on the performance of the supply chain as a whole. All or some of the business partners in a supply chain, particularly logistics service providers, will encounter some or all of the risks or conditions that exist in the South African business environment, which will have a negative impact on the whole supply chain (BadenhorstWeiss \& Waugh 2014:284). 


\section{The important role of logistics in the economy}

Total logistics costs formed $12.5 \%$ or R393 billion of South Africa's gross domestic product (GDP) in 2012 and it was estimated to be R423 billion in 2013 and R470 billion in 2014 (State of Logistics Survey 2014:ii). The important role of logistics in the country's economy is captured succinctly in the following:

The performance and growth of the South African logistics industry are both inputs to and outflows from the performance and growth of the South African economy - especially in the primary and secondary sectors. The exchange rate, inflation rate and interest rate directly impact the cost performance of the logistics industry. Other macro-economic issues such as the structure of the South African economy, balance of payments, budget deficits and human resources problems affect the economy as a whole, which influence the demand for logistics services. Simultaneously, the performance of the logistics industry - specifically the cost of logistics - has a bearing on the global competitiveness of South African industries. (State of Logistics Survey 2014:n.p.)

South Africa's competitiveness was ranked 53rd out of 148 countries by the World Economic Forum (2014). South Africa thus has a modern economy and a well-developed logistics infrastructure and system. However, shortcomings and risks are noticeable and becoming more evident. As mentioned previously, South Africa's LPI has decreased to 34th out of 160 countries in 2014 from 23rd out of 155 countries in 2012. Of the six factors considered by the World Bank for the LPI, customs ranked 42nd compared to 26th in 2012; tracking and tracing ranked 41st compared to 16th in 2012; infrastructure ranked 38th compared to 19th in 2012 (The World Bank 2012, 2014). Clearly the indicators are all going the wrong direction and this should be a matter of concern (Badenhorst-Weiss \& Waugh 2014:284).

\section{Problem statement and purpose of study}

South African supply chains are exposed to numerous risk factors, constraints, complexities and uncertainties in the business environment that impact their efficiency and effectiveness and thus their competiveness. Unless identified and proactively and successfully addressed or managed, these risks and constraints in the business environment will negatively impact supply chains and logistics operators' efficiency and effectiveness (Badenhorst-Weiss \& Waugh 2014:284). The purpose of this research was to explore risk factors in the South African business environment that negatively affect the efficiency and effectiveness of logistics operators in supply chains, using the explorative mixed method.

\section{Research strategy Research approach and design}

The sequential mixed method was used in this study. This method consists of either a quantitative and qualitative (quant-qual) study or a qualitative and quantitative (qualquant) study. Mixed method studies present a pragmatic world view. With this method diverse types of data are collected which lead to an understanding of the research problem (Creswell 2009:18):

The quant-qual study begins with a broad survey in order to generalise results to a population and then, in a second phase, focuses on qualitative, open-ended interviews to collect detailed views from participants. (Creswell 2009:18)

The quantitative study of this research study was conducted in the form of a survey and the qualitative study in the form of a focus group discussion. To adapt the questionnaire content for the qualitative study, the items (or questions) in the questionnaire were categorised by the researchers to form the themes or topics for the focus group discussions. A third element in the form of available literature of mainly supply chain industry related reports and magazines were integrated to compare the findings.

\section{Quantitative study}

In order to identify and understand key risk factors that cargo owners and logistics service providers are facing in the South African business environment, the SASC identified a need for research into these issues. The SASC members include mostly large cargo owners and logistics service providers in South Africa. (Cargo owners are involved in logistics activities for their own goods [cargo], and the service providers offer logistics services to other organisations.) These cargo owners and service providers are confronted daily with hurdles in the business environment that influence their efficiency, effectiveness, customer service and eventually the competitiveness of the whole supply chain (Badenhorst-Weiss \& Waugh 2014:285). Through discussions at various meetings SASC members identified risk factors and constraints that they viewed as straining the effectiveness and efficiency of South African supply chains. Nineteen (19) business environment risk factors were identified and included in the questionnaire. The questionnaire was discussed with the researchers and a statistical consultant and enhanced several times before finalisation and was tested to ensure the validity of the instrument. The survey was conducted in 2013 among members of the SASC, the Chartered Institute of Logistics and Transport in South Africa (CILTSA) and the Transport Forum (Badenhorst-Weiss \& Waugh 2014:285). The selfadministered questionnaire was distributed by email to more than a thousand of members of these associations (which constituted the sample population). Follow-up emails were sent to increase the low response rate. Due to strict research ethics rules at the institution the researchers are attached to, the researchers could not use methods such as further emails, putting pressure on the individuals to respond or offer incentives to increase the response rate. Therefore, unfortunately, only 51 usable responses were received. The resulting low response rate limits the generalisation of the findings. Despite the low response rate and the resultant bias it was decided to continue with the capturing of the data, since the findings of the survey formed only one of the inputs 
to the study. The completed questionnaires were checked for inconsistencies and omissions and the captured data was processed and analysed using SPSS (Badenhorst-Weiss \& Waugh 2014:285).

\section{Qualitative study}

Qualitative studies are not often done in logistics research. Naslund (2002) stated that logistics researchers also need to do qualitative studies: 'Furthermore, if we truly want to develop logistics, to develop new theories and ideas, then we need to question our paradigms, methodologies and choice of methods.'

The qualitative study was conducted by means of a focus group discussion. The topics or themes to be discussed were identified from the findings of the quantitative study. A focus group is defined by Cooper and Schindler (2008) as:

[ $t$ ] he simultaneous involvement of a small number of research participants (usually 8 to 10) who interact at the direction of a moderator to generate data on a particular issue or topic, widely used in explorative studies and usually last 90 minutes to two hours. (p. 704)

According to Cooper and Schindler (2011:162), the sample design of a qualitative study can be non-probability or purposive and the sample size small. With non-probability or purposive sampling not all the individuals in the population will get an equal chance to be selected (Zikmund et al. 2013:392). This implies that researchers have the freedom to choose participants subjectively, that is, each member of the population does not have a known chance of being included (Cooper \& Schindler 2008:379). 'Purposive sampling is used so that individuals are selected because they have experienced the central phenomenon' (Creswell 2009:217).

The focus group discussion was held at the 2013 Annual SAPICS Conference in June 2013. The focus group discussion was included as a workshop in the conference programme, parallel with other workshops (Badenhorst-Weiss \& Waugh 2014:285). The topic and purpose of the workshop were clearly indicated in the conference programme and one may therefore assume that the participants who pitched for the workshop were interested in the topic and had something to contribute. (This clearly indicates non-probability or purposive sampling.) The focus group discussion was attended by 23 participants. They were asked to introduce themselves and indicate for which organisation they worked and what they did. Most participants worked for prominent logistics companies in the private and public sectors. There was an almost equal distribution between logistics service providers and cargo owners represented. Because they were not part of the qualitative study no representative of SASC attended the focus group discussion.

The participants voluntarily took part in the focus group discussion. The participants were asked to choose a theme and to divide into smaller groups to discuss a selected theme. The themes (representing the content of the questionnaire) included (1) infrastructure issues, (2) operational issues, (3) human resource issues and (4) supply chain costs. The participants were asked to also consider and discuss possible actions to mitigate the risk factors. Each small group brainstormed their selected theme and then reconvened to report back with the aid of flip charts. The whole group (23) was asked to give inputs to the smaller groups' presentations. The researchers made field notes during the discussions and feedback session. The field notes and the flip charts were used by the researchers to transcribe the 'proceedings'. This was emailed to all the participants to ensure that the 'proceedings' were an accurate reflection of the group discussions (Badenhorst-Weiss \& Waugh 2014:285-286) - a process called 'member checking', with the aim to improve trustworthiness (Creswell 2009:191-192). Through the focus group discussion, 'additional information was gathered and insight generated' (Salkind 2012).

\section{Appropriate literature}

In line with the practical origin and orientation of the research study the literature consisted mainly of industry articles and research reports. According to Creswell (2009:27), the literature in a qualitative study may be presented at the end and form a basis for comparing and contrasting findings of the qualitative study. Therefore, the literature does not guide and direct the study, but becomes an aid once patterns of categories or themes have been identified.

Consequently, the findings of the qualitative study and appropriate industry literature will be integrated after a brief outline of the survey findings (Badenhorst-Weiss \& Waugh 2014:286)

\section{Survey and results}

\section{Profile of respondents}

Of the 51 respondents, $46 \%$ were cargo owners, $42 \%$ were logistics service providers and $12 \%$ were both cargo owners and logistics providers. The respondents were mostly large businesses in terms of annual turnover of logistics activities $45 \%$ of the respondents were from companies generating more than R500 million per annum and 31.5\% from R10 million to R500 million (which are regarded as large businesses in South Africa). These respondents came mainly from the transport and logistics (37\%), manufacturing (16\%), mining (13\%) and agricultural (12\%) sectors. The majority of the respondents were relatively large movers of materials. About $50 \%$ of the respondents moved more than 500000 tonnes annually. In terms of containers moved, there is an even spread, with $37 \%$ moving more than 1000 containers annually, 29\% between 100 and 1000 containers, and 27.5\% below 100 containers annually (Badenhorst-Weiss \& Waugh 2014:286). From the profile it is clear that the majority of the respondents are relatively large logistics providers and cargo owners, thus having a substantial economic impact.

The respondents clearly favoured road transport: $60.8 \%$ of the respondents indicated that they used road transport to 
move between $40 \%$ and $100 \%$ of their cargo, followed by maritime transport (43.2\%). The Durban harbour is mostly used for exporting: $43.2 \%$ of the respondents used this harbour for between $40 \%$ and $100 \%$ of their total export cargo (Badenhorst-Weiss \& Waugh 2014:286).

The respondents were therefore mainly large logistics and mining companies, large movers of cargo that mainly use road transportation. Durban harbour is mostly used by respondents for exports.

\section{Factors and risks in the business environment}

The respondents had to indicate to what extent the risk factors posed serious challenges to their organisation and thus their supply chain. A four-point scale - from no extent (1); to a small extent (2); to a moderate extent (3); to a large extent (4) was used (Badenhorst-Weiss \& Waugh 2014:286).

Table 1 reflects a summary of the importance of risk factors (19 items in the questionnaire) for the respondents of the survey, from a moderate to a large extent (rated 3 and 4).

From Table 1 the major issues of concern for the respondents of the survey became clear. They indicated the following as problems from moderate to high (rated above 80\%) (Badenhorst-Weiss \& Waugh 2014:286):

- Operational inefficiencies in infrastructure, 92\% $(55 \%$ indicated a problem to a large extent).

- Human resources problems, $80 \% \quad(47 \%$ indicated a problem to a large extent).

- Increasing transportation costs, 95\% (73\% indicated a problem to a large extent).

- Labour relations in industry, 89\% (77\% indicated a problem to a large extent).

Other risk factors identified by $70 \%-80 \%$ of the respondents were: Infrastructure quality in South Africa (78\%); Road versus rail options (70\%); Increased toll roads and e-tolling (79\%) $(57 \%$ of respondents indicated it as a problem to a large extent); Lack of regional integration and harmonisation (71\%); Cross-border inefficiencies (76\%) (46\% of respondents indicated it as a problem to a large extent); Private sector engagement with government (72\%) (Badenhorst-Weiss \& Waugh 2014:287).

Besides the rating of the risk factors the respondents were also asked to rank the top five risk factors (19 possibilities) of concern ( 1 is ranked the most important and 5 the fifth most important problem). The ranking is as indicated in Table 2.

From Table 2 it is clear that infrastructure quality in South Africa ranked the highest (i.e. the number one risk factor) by $37.3 \%$ of the respondents. The second most important risk ranked was operational inefficiencies (35.3\%) and then increasing transportation costs $(27.4 \%)$. Fourth most important was labour relations and fifth the shortage of skilled and experienced staff.
TABLE 1: Supply chain environmental risks of concern.

\begin{tabular}{|c|c|}
\hline Issues & $\begin{array}{l}\% \text { Problematic from } \\
\text { moderate to large extent }\end{array}$ \\
\hline Infrastructure quality in South Africa & 78 \\
\hline Operational issues in South Africa & 92 \\
\hline Infrastructure quality in southern Africa & 68 \\
\hline Operational issues in southern Africa & 66 \\
\hline Human resources problems & 80 \\
\hline Shortage of skilled and experienced supply chain staff & 68 \\
\hline Increasing transportation costs & 95 \\
\hline Road versus rail options & 70 \\
\hline Introduction of carbon tax & 68 \\
\hline Increasing toll roads and e-tolling & 79 \\
\hline Lack of law enforcement & 64 \\
\hline $\begin{array}{l}\text { Corruption in logistics activities in supply chains in } \\
\text { South Africa }\end{array}$ & 50 \\
\hline $\begin{array}{l}\text { Corruption in logistics activities in supply chains in } \\
\text { southern Africa }\end{array}$ & 55 \\
\hline Lack of regional integration and harmonisation & 71 \\
\hline Cross-border inefficiency & 76 \\
\hline Private sector engagement with government & 72 \\
\hline Customs/SARS inefficiencies & 50 \\
\hline Labour relations in industry & 89 \\
\hline BEEE and Transportation Charter & 61 \\
\hline
\end{tabular}

Source: Badenhorst-Weiss, J.A. \& Waugh, B.J., 2014, 'Business environmental factors affecting South Africa's supply chains and economic growth and development', Problems and Perspectives in Management 12(4), 286

TABLE 2: Ranking of most important supply chain risks or problems.

\begin{tabular}{lll}
\hline Importance ranking & Risk factor & Percentage \\
\hline 1 & Infrastructure quality in South Africa & 37.3 \\
2 & Operational inefficiencies in South Africa & 35.5 \\
3 & Increasing transportation costs & 27.4 \\
4 & Labour relations in industry & 13 \\
5 & $\begin{array}{l}\text { Shortage of skilled and experienced } \\
\text { supply chain staff }\end{array}$ & 8 \\
\hline
\end{tabular}

Source: Badenhorst-Weiss, J.A. \& Waugh, B.J., 2014, 'Business environmental factors affecting South Africa's supply chains and economic growth and development', Problems and Perspectives in Management 12(4), 287

By reconciling the rating and ranking of the issues of most concern, the following four can be regarded as the top factors that justify further discussion in the paper, and further research:

- infrastructure

- operational inefficiencies

- human resources (including labour relations)

- costs.

Due to a small number of responses of the survey and the structure of the questionnaire, a limited possibility for inferential statistics existed. The inferential statistics that could be done were on significant differences between cargo owners and logistics service providers, which had shown differences in a limited number of areas, but this falls outside the scope of this article (Badenhorst-Weiss \& Waugh 2014:287).

\section{Qualitative findings and literature}

As indicated previously, mainly practice-related literature was used in this article and it will be discussed with the qualitative study findings. According to Creswell (2009:27), the literature used in a qualitative study may be integrated with the qualitative study findings. 


\section{Theme 1: Infrastructure as an area of concern}

In literature it was concluded that:

[ $t$ ]he performance of South Africa's logistics industry is very dependent on its transport infrastructure, logistics service provision, cross-border trade facilitation and telecommunications system. Transport infrastructure, arguably the most important component of these, is a critical ingredient for economic growth, development and wealth creation. Transport infrastructure investments are key determinants of performance in the transport sector. (State of Logistics Survey 2014:28)

'Infrastructure planning should take the operational characteristics and needs of logistics systems into account' (Viljoen 2012:1).

The focus group agreed that South Africa has generally a good infrastructure (e.g. world class ports and harbours); however, the operations within these are poor. In a sense Transnet Freight Rail has a fairly good infrastructure; however it has not been adequately maintained and extended and therefore there are many capacity and reliability problems. Consequently, this has contributed to road transport increasing (doubled in a few years) with a negative influence on the quality of the roads, which have not been maintained adequately to keep up with the level of usage (BadenhorstWeiss \& Waugh 2014:287). The focus group felt that there is a general lack of accountability within government institutions and inadequate action plans for engagement with the private sector in the provisioning of transportation infrastructure. Government should allow the private sector to participate more in the provision of infrastructure, particularly rail. There is at some places a misalignment between infrastructure provided and the demand for it. Many organisations have a need for rail transport, particularly for their bulk transport requirements. South Africa, in comparison with other African countries, has a well-developed infrastructure, but when trade is extended to the neighbouring and other African countries, infrastructure becomes a problem, to the detriment of trade and economic development of the region (Badenhorst-Weiss \& Waugh 2014:287).

Since the study has been conducted there are signs that Transnet has realised the importance of private sector involvement in the development of additional rail infrastructure. They have invited the private sector for discussions on these matters and a good response followed (Ensor 2014). However, no evidence could be found that there is any progress in this regard. It seems that Transnet is reluctant to venture in such private sector partnerships.

\section{Theme 2: Operational inefficiencies as an area of concern}

In the focus group discussion several inefficiencies in the operation of the logistics system were mentioned. The focus group was of the opinion that Transnet is partly to blame for operational inefficiencies. They feel that there is a lack of communication between the various Transnet divisions, and this leads to bad planning and inefficiencies. There are problems in cross-border operations, particularly with regard to law enforcement and corruption and other operational issues which are 'killing business'. Much more could be done with regard to the standardisation of documentation between the countries and upfront communication through, for example, an efficient information system indicating when vehicles are due to arrive at border posts. This could also lead to less corruption and efficient crossing of the borders. Skills development of border personnel and harmonisation of infrastructure between South Africa and its neighbouring countries would also lead to more efficient supply chains and economic development in the region. The development of consolidation hubs where advanced planning and better decision-making could be ensured regarding the use of road or rail should be pursued (Badenhorst-Weiss \& Waugh 2014:288).

In a survey undertaken by the Freight and Trade Weekly (FTW) regarding service levels in the logistics industry, the respondents had to rate the service levels of South African ports, shipping lines, warehousing, transport operators, logistics providers, consolidators and airfreight on a scale of 1 to $10(1=$ poor and $10=$ excellent $)$. The service levels were all rated between 5 and 6.5 except for South African ports, which were rated at 3.94, mainly due to low morale, low productivity and inadequate skills of workers. Also, 54\% of the respondents felt that service levels had deteriorated over the past 3 years (Orlek 2013:4). 'Both good service delivery in the logistics environment and good infrastructure are under pressure in the country' (State of Logistics Survey 2014).

\section{Theme 3: Human resources as an area of concern}

The Barloworld Logistics (2014) report indicated that a shortage of skills in South Africa is the 4th highest supply chain constraint. A general shortage of a skilled workforce in South Africa, not only in the logistics and supply chain areas, is hampering economic growth. The World Economic Forum (WEF) (2014) identified an inadequately educated workforce as the most problematic factor for doing business in South Africa. Linked to human resources problems the WEF indicated that the quality of the education system is very poor (ranked 146th of 148 countries), labour market efficiency is poor (116th), hiring and firing practices are extremely rigid (147th), whilst wage determination is inflexible (144th) and significant tension exists in labour-employer relations (148th).

The focus group noted a lack of skills, particularly supply chain, communication and engineering skills. There are also major concerns with regard to the need for up-skilling of people through education, encouraging companies to comply with, or adhere to, the transferring of skills, collaboration and exchange programmes with international institutions and organisations. Transferring of skills and the mentorship of employees should be ingrained in the fibres of all corporate culture. There should also be a drive to retain employees who have received education and training while 
employed by an organisation, in an organisation, preferably in a particular position for a number of years in order to reap the benefits of the investment made. Finally, there need to be on-going education, training and development of graduates and therefore a culture of continuous up-skilling. The lack of skilled personnel on all levels hampers the performance of supply chains (Badenhorst-Weiss \& Waugh 2014:288).

From an industry survey it appears that tertiary degrees and professional certifications teach students the required 'hard' skills for day-to-day supply chain work, but there is a great gap in terms of 'soft' skills and practical exposure (State of Logistics Survey 2014:83). The previously-mentioned FTW survey regarding service levels in the logistics industry points to (1) the overall quality of staff which seem to lack training with no insight into the results of their actions, (2) service levels in the freight industry which appear to be far from satisfactory with the dearth of skilled staff at the root of the problem and (3) overall knowledge and problem-solving skills being the greatest problem (Orlek 2013:4).

With regard to labour relations in the industry, it was noted by the focus group that the outsourcing of some services and the use of labour brokers can be problematic and can lead to salary issues and strikes. It was felt that labour brokers are often involved in questionable human resources practices which could lead to unacceptable working conditions; that the actions of the various unions and bargaining councils were questionable; and that working conditions, security and safety and the use of migrant workers as opposed to locals were also becoming major issues, particularly with respect to a perceived lack of loyalty by the migrant workers toward the country (Badenhorst-Weiss \& Waugh 2014:289).

Brandt (2014:32) referred to the issue of labour relations as 'the country's well-chronicled labour tensions' and noted that constraints in labour relations had an extremely negative impact on the country's supply chains and therefore economic growth and development. Bell (2014:23) ascribed this to a legacy of decades of neglect, mistakes, and insensitivity on behalf of employers, unions and all tiers of government, with the actions of labourers partaking in lengthy strikes leading to them suffering desperate hardship. He (Bell 2014) also noted that:

this trend is likely to be repeated and exacerbated, with increased mechanisation and consequent job losses; unless prompt and sensitive action is taken to improve the lives of the labour force, the future will remain troubled. (p. 23)

However, at the same time the challenge is to manage labour costs and improve skills (Storey \& Urquhart 2014:30-32). Labour unrest remains a concern across most industry sectors (Barloworld Logistics 2014). Organisations are thus increasingly seeking to protect their supply chains against the risk of interruptions to their businesses and supply chains through strikes and riots (Odendaal 2013:34-35). Reimers (2014:6-7) noted that addressing problematic labour relations is the first step for an organisation in mitigating their risk profile, and has a significant impact on supply chain resilience, as well as business profitability and reputation. The bottom line is that, together with infrastructure and operational constraints and rising costs, labour disputes remain the biggest inhibitors of Africa's growth. Unrest and shortages of skilled labour have to be addressed (Venter 2013:33).

\section{Theme 4: Costs as an area of concern}

The performance of the logistics industry, specifically the cost of logistics, has a bearing on the global competitiveness of South African industries (Badenhorst-Weiss \& Waugh 2014:289). Total logistics costs amounted to R393 billion in 2012 (12.5\% of GDP), and is estimated to amount to R423 billion in 2013, whilst R470 billion is the estimate for 2014 (State of Logistics Survey 2014:ii).

In addition to transport costs, the focus group indicated that all the other problems experienced in supply chains have cost implications, such as the lack of quality or adequate infrastructure, human resources capacity, labour relations and operational inefficiencies (Badenhorst-Weiss \& Waugh 2014:289).

Barloworld Logistics (2014) ranked the top supply chain constraint as the cost of transport. The road freight industry in South Africa has also registered concern, as they see costs escalate in the form of tolls, fuel and taxes, as well as fees across the borders, and the introduction of carbon taxes set in the near future (Ittmann 2012:24; Venter 2013:33).

According to the State of Logistics Survey (2014), the largest component of total logistics costs in South Africa is transportation costs. The soaring price of fuel and a trend in the growth of management and administration costs, due to more employees (excluding vehicle drivers) in the transport sector, with an associated growth in the wages of these individuals that is above the inflation rate, are the main contributors to increased transportation costs. Shifting from road to rail will have a positive effect on fuel consumption. Savings in emissions and accidents, congestion and better road safety will be additional benefits when a shift from road to rail takes place on a large scale (State of Logistics Survey 2014).

\section{Conclusion}

This article reported on a sequential mixed method study that had been conducted in the logistics industry. This methodology is not often used in logistics research. In the first part of the study - the survey - it was found that operational inefficiencies of infrastructure, lack of sufficiently educated and skilled human resources, increasing transportation cost and labour relations in the industry are the most important factors or risks in the business environment. There is to a large extent agreement between the findings of the survey, industry literature and other studies such as the State of Logistics Survey and the Barloworld Logistics surveys regarding the main factors and risks in the South African business environment which have an impact on the effectiveness of organisations and supply chains. 
The survey was followed by a focus group discussion, where participants from the logistics industry further discussed these factors. Although many of the opinions expressed in the focus group were reflected in industry literature, some unique ideas were raised. Reflecting on the methodology used in the study the researchers are confident that it is a useful methodology for future research.

Environment risks are not controllable by individual businesses and supply chains. However, the better they understand the risks, the better they can manage their businesses and supply chains to reduce the impact of these risks. Some of the causes and impacts of risk factors can be laid at the door of the government and should be addressed by government, preferably in partnership with the private sector. Areas that need urgently the government's attention are, for example, rail infrastructure, fuel levies, labour legislation and stability, and education. Labour laws, for example, hiring and firing, are too strict and this gives rise to the extensive use of labour brokers, which is widely unpopular, particularly with labour unions and workers. This gives rise to labour unrest.

The success of logistics industry and the economy is dependent on infrastructure. It was found that South Africa has fairly good infrastructure, but the infrastructure is not adequately extended and maintained to comply with the demand (e.g. rail), which leads to the exploitation of other infrastructure (e.g. roads). There is also a misalignment between fairly good infrastructure in South Africa and its neighbouring countries, which impacts the efficiency and effectiveness of supply chains and constrains the economic development of the whole southern Africa region. There was consensus that government cannot do it on its own and needs to provide it in partnership with the private sector. A move from road to rail of heavy cargo should thus be promoted as a possibility in the foreseeable future, which will alleviate many of the risks of road surface damage, heavy traffic, toll fees, fines, accidents, hijackings and insurance costs. Infrastructure development of neighbouring countries should be high on the agenda of the Southern Africa Development Community (SADC) (Badenhorst-Weiss \& Waugh 2014:291).

Whether fairly or unfairly - Transnet is mainly blamed for operational inefficiencies. There is an apparent lack of coordination between divisions, whilst the harbours provide a poor service. Another main risk factor for the logistics industry is inefficiencies and corruption during bordercrossings. Standardisation of documentation between the southern Africa countries and skills development of border personnel is suggested. A consolidation hub and communication system through which advanced communication about cargo to be moved across borders are suggested. Such hub should preferably be developed through a consortium of private logistics providers and cargo owners. A properly developed railway network in the southern Africa region can facilitate trade between the countries and decrease bottlenecks and exposure to corruption by officials at the borders. Businesses and supply chains should consider possible delays at border posts as well as ports in planning delivery dates (Badenhorst-Weiss \& Waugh 2014:291).

A skilled, educated and efficient workforce remains a large problem in South Africa and the logistics industry. Supply chains operating in South Africa must therefore invest in the education, development, up-skilling and mentoring of their workforce and make an effort to retain them. Labour relations, and particularly strikes and unrest, is a serious risk factor in all industries in South Africa. Blame for the volatile situation could lie with a combination of the use of labour brokers, bargaining councils, labour unions, working conditions and the use of migrant workers. Supply chain operators can consider mechanisation in order to alleviate this risk, but there will always be a human factor in any operation. Investment in the social well-being of the labour force is essential (Badenhorst-Weiss \& Waugh 2014:291).

Transportation cost is a serious problem impacting the competitiveness of supply chains. The exorbitant increase in transportation costs is mainly caused by the cost of fuel, a larger workforce and (above inflation) increasing salaries. The fuel price is determined by government and a major component of the fuel price consists of fuel taxes. Therefore the logistics industry has no control over this. Supply chain players can only alleviate the situation by better planning of loads and routes and forming partnerships with other transporters to assure full forward and return loads. Inadequate infrastructure and human resources capacity, including labour unrest and strikes, and operational inefficiencies have cost implications for logistics organisations. The increase in the workforce in the transport sector and higher salaries can be alleviated by the development of employees in order to improve their productivity and to retain skilled staff through a positive corporate culture (Badenhorst-Weiss \& Waugh 2014:291).

In conclusion, it seems that operational inefficiencies at ports and across borders, reliable rail infrastructure and costs are particularly problematic for organisations and supply chains. In addition, human resources, particularly a lack of appropriate skills and labour relations, are the most serious risks in the business environment for supply chain competitiveness and economic growth of the country and region. Individual businesses and supply chains must manage their transport costs better by better route planning, full loads and partnerships with other logistics companies. Businesses and supply chains must invest in human resource development, mentorship and motivation through corporate culture (loyalty and pleasant working environment) instead of unbalanced or large increases in salaries of administrative and managing staff (Badenhorst-Weiss \& Waugh 2014:291).

\section{Limitations of the study and further research opportunities}

Two years after the findings of this study in 2013 one can reflect and notice how volatile factors and risks within the business environment are. Although it is now acknowledged that an electricity crises was looming over the past few years, 
none of the research initiators, researchers and participants in the study regarded electricity provision as a risk factor that influence their supply chain competitiveness. One new crisis such as electricity does not alleviate the importance of any of the other business environment hindrances or risk factors. In any study of this nature the importance (ranking) of risk factors may change overnight. This is in the nature of risks and supply chains are particularly vulnerable. This opens up new research opportunities and questions such as 'What is the influence of the electricity crisis on the logistics industry and supply chains?'

In addition, only 51 respondents completed the questionnaire. Consequently, the survey could not be seen as representative of all logistics providers or cargo owners. The respondents are mainly large businesses, and inputs from smaller logistics service providers may impact the results of the study. This shortcoming opens opportunities for further research among smaller logistics operators. The emphasis of this article was on the use of the explorative mixed method, and even though the response rate from the survey was low, and thus not representative, it was important to demonstrate the use and results obtained from the explorative mixed method.

Inferential statistics (not included in this article) showed significant differences between cargo owners and logistics service providers in a number of risk areas. This was not further explored in the quantitative study. Future research may be done to distinguish the views of cargo owners and logistics service providers regarding important businessenvironmental risk factors, perhaps by dividing the focus group in two - logistics service providers and cargo owners.

Finally, the use of the explorative mixed method in obtaining quantitative and qualitative inputs and integrating these results with existing literature proved to be a workable and very usable methodology.

\section{Acknowledgements Competing interests}

The authors declare that they have no financial or personal relationship(s) that may have inappropriately influenced them in writing this article.

\section{Authors' contributions}

Both authors made an equal contribution. J.A.B-W. (University of South Africa) was an equal partner in both conducting the empirical research and writing the article, including conceptualisation, literature search and theoretical discussion, research design, presentation the findings and conclusions, and preparing the article for submission. B.J.W. (University of South Africa) liaised with SA Shippers
Council about their need for the research and discussed the research instrument with them. In addition she was an equal partner in conducting the research and writing the article, including conceptualisation, literature search and theoretical discussion, research design and presented the findings and conclusions, and preparing the article for submission.

\section{References}

Badenhorst-Weiss, J.A. \& Waugh, B.J., 2014, 'Business environmental factors affecting South Africa's supply chains and economic growth and development', Problems and Perspectives in Management 12(4), 238-291.

Barloworld Logistics, 2013, 'Serial innovation, smart partnerships and sustainable advantages', Supplychainforesight, Research Report, Johannesburg.

Barloworld Logistics, 2014, 'The rise and fall of customers and companies', Supplychainforesight, Research Report, Johannesburg.

Bell, T., 2014, 'Lessons from Marikana remain unlearnt', The WITS Business School Journal: Working Force issue 37, p. 23.

Brandt, C., 2014, 'The tide turns', Africa Investor, May-June, 12(3), 32-33.

Bredell, R. \& Walters, J., 2007, 'Integrated supply chain risk management', Journal of Transport and Supply Chain Management 1(1), 1-17. http://dx.doi.org/10.4102/ jtscm.v1i1.3

Burt, D., Petcavage, S. \& Pinkerton, R., 2010, Supply management, McGraw-Hill, New York, NY.

Cooper, D.R. \& Schindler, P.S., 2008, Business research methods, 10th edn., McGrawHill, Singapore.

Cooper, D.R. \& Schindler, P.S., 2011, Business research methods, 11th edn., McGrawHill, Singapore.

Creswell, J.W., 2009, Research design: Qualitative, quantitative and mixed methods approaches, Sage, Thousand Oaks, CA.

Ensor, L., 2014, 'Rail investment call well received', BDlive, viewed 14 August 2014, from http://www.bdlive.co.za/business/transport/2014/08/08/rail_investment call_well_received

Gattorna, J., 2010, Dynamic supply chains: Delivering value through people, Pearson, Harlow.

Hailey, M. \& Jonasson, M., 2013, 'Risk management in air freight handling processes', Unpublished Master's thesis, Business Administration, Jönköping International Business School.

Ittmann, H.W., 2012, 'Introduction', in 8th Annual State of Logistics Survey for South Africa, Council for Scientific and Industrial Research (CSIR), Pretoria.

Naslund, D., 2002, 'Logistics need qualitative research', International Journal of Physical Distribution and Logistics Management 32(5), 321-338. http://dx.doi. org/10.1108/09600030210434143

Odendaal, W., 2013, 'Protect your supply chain', Supply Chain Today, 22 August, 34-35.

Orlek, J., 2013, 'Survey paints dismal picture of service levels in the industry', Freight and Trading Weekly, 01 March, p. 4.

Pienaar, W.J. \& Vogt, J.J., 2012, Business logistics management: A value chain perspective, Oxford, Cape Town.

Reimers, H., 2014, 'Strategic plan critical to deal with supply chain disruptions', Freight and Trade Weekly, 10 July, pp. 6-7.

Salkind, N.J., 2012, Exploring research, Pearson, NJ.

Simpson, Z. \& Havenga, J., 2012, 'National land freight transport activity', in 8th Annual State of Logistics Survey for South Africa, Council for Scientific and Industrial Research (CSIR), Pretoria.

State of Logistics Survey, 2014, in 10th annual State of Logistics Survey for South Africa 2013, Council for Scientific and Industrial Research (CSIR), Pretoria.

Storey, D. \& Urquhart, D., 2014, 'Fighting the war for talent on two fronts', The WITS Business School Journal: Human Capital 37, 30-32.

The World Bank, 2012, Global Rankings 2012: Logistics Performance Index, viewed 05 July 2015, from http:// www.lpi.worldbank.org/international/global/2012

The World Bank, 2014, Global Rankings 2014: Logistics Performance Index, viewed 05 July 2015, from http://www.lpi.worldbank.org/international/global

The World Economic Forum, 2014, Global Competitiveness Report 2013-2014, viewed 19 August 2015, from http://www.weforum.org./reports/global-competitivenessreport-2013-2014

Venter, L., 2013, 'What's stifling Africa's growth', Freight and Trading Weekly, 15 November, p. 33.

Viljoen, N., 2012, 'Executive summary', in 8th Annual State of Logistics Survey for South Africa, Council for Scientific and Industrial Research (CSIR), Pretoria.

Zikmund, W.G., Babin, B.J., Carr, J.C. \& Griffen, M., 2013, Business research methods, South-Western Cengage Learning. 